\title{
Review
}

\section{Impact of pancreas transplantation on diabetic secondary complications and quality of life}

\author{
R . L andgraf \\ D epartment of Internal M edicine, Innenstadt K linikum, U niversity of M unich, M unich, G ermany
}

\section{Rationale for pancreas transplantation}

D iabetes mellitus is a growing worldwide health problem often leading to medical and psychosocial disasters including blindness, amputations, coronary artery disease, stroke and kidney failure among others [1]. A lthough the possibilities of training and treating, particularly young, motivated insulin-dependent diabetic (IDDM) patients are numerous and sophisticated, none are able to normalise the metabolism of people who have been diabetes for years or even decades $[2,3]$ even though this is a prerequisite for the prevention of secondary diabetic complications. In addition, modern therapy of IDDM is laborious and troublesome for the patient and a formidable task for the physician. E ven if the patient and his/her doctors do their best, they are rarely rewarded by a stable metabolic state without hypoglycaemia and without the appearance of severe complications. Therefore, much research effort has been undertaken to develop a patient-controlled endogenous source of insulin and other islet cell hormones in order to improve quality of life and to prevent, stabilise or reverse secondary complications. There are three directions for possible therapeutic interventions:

1. human vascularised pancreatic transplantation [4];

2. transplantation of adult islets or fetal pancreatic tissue from humans or other species (xenotransplantation) as free grafts or separated by an immune barrier $[5,6]$;

3. implantation of an artificial mechanical device which should be able to imitate at least some

Corresponding author: Prof. Dr. R üdiger L andgraf, D epartment of Internal M edicine, Innenstadt K linikum, Z iemssenstrasse 1, D -80336 M ünchen, G ermany

Part of this manuscript was presented in the Camillo-Golgi Lecture at the 31st A nnual Meeting of the EA SD in Stockholm 1995 functions of the islet, namely glucose sensing and insulin delivery [7].

Since the first report on implantation of sheep pancreas into an ID D M patient in 1894 [8] much research has been performed to provide the patient with an endogenous source of insulin and other islet cell hormones. So far, only pancreatic grafting is able to restore normal metabolism for long periods [9]. Pancreatic transplantation started in many centres in the early 1980 s when cyclosporin entered the therapeutic field of organ transplantation and steadily increased to reach more than 6800 pancreas transplant recipients according to the International Pancreas Transplant R egistry [10]. A Iso the success rates of grafting increased impressively: the 10-year pancreas graft survival rate is $76 \%$ and that of the patients is $90 \%$ [10]. Long-term metabolic control in patients after successful pancreatic grafting is impressive as judged by daily blood glucose levels, glycated haemoglobin values and glucose tolerance tests [11-13] and is superior to intensified insulin treatment $[2,3,14]$. Most important, optimal glucose control can be achieved without the danger of acute metabolic derangements such as severe and recurrent hypoglycaemia.

The natural course of development of diabetesspecific complications is depicted in Figure 1. A fter 5 to 8 years diabetic complications appear and 20 to 25 years after onset of the disease many patients suffer from severe problems. In recently published prospective studies in ID D M patients $[2,3,15]$ intensified insulin treatment was started mostly much earlier. In contrast pancreatic grafting is performed almost exclusively in patients undergoing chronic dialysis together with a kidney transplantation, which is on average 22 years after onset of diabetes.

In recent years the number of thoroughly investigated pancreas graft recipients has increased considerably. However, the data from the different centres 


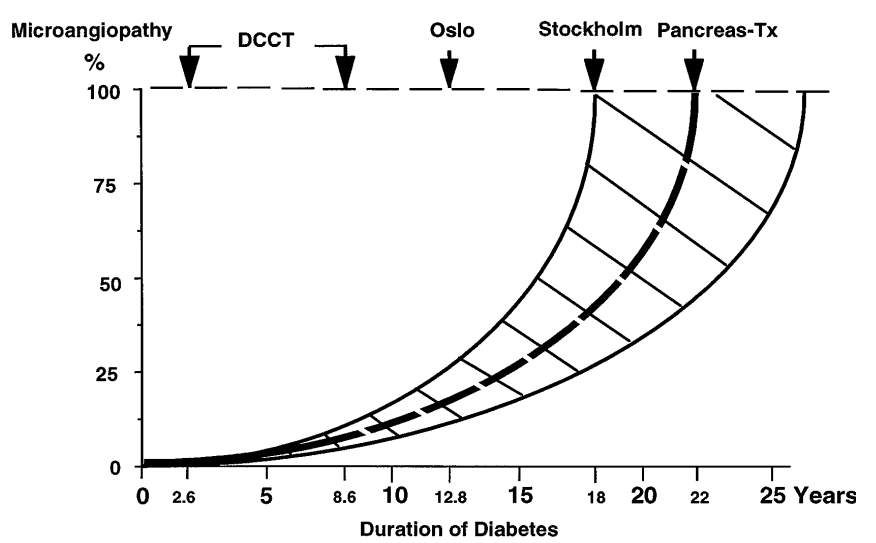

Fig. 1. Illustration of the natural time course of the development of diabetic microangiopathy. Primary and secondary intervention with intensified insulin therapy started early at a mean of 2.6 and 8.6 years after diagnosis in the DCCT study [2], 12.6 in the 0 slo [72] and 18 years after manifestation of diabetes in the Stockholm study [33]. In contrast pancreas transplantation with subsequent normalization of glucose metabolism is performed at a mean duration of diabetes of 22 years

are often not easy to compare, mainly due to the lack of universally accepted study protocols, inhomogeneous patient groups especially concerning renal function, metabolic control and the degree of multimorbidity as well as the number of cases investigated.

It is the purpose of this review to analyse in detail the impact of pancreatic grafting on secondary complications and on quality of life.

H owever, it is out of the scope of this work to discuss the intermediary metabolism after pancreatic grafting.

\section{Retinopathy}

A fter the first report of a favourable effect of pancreatic grafting on diabetic retinopathy [16], conflicting results have been published. For example, in the study by R amsay and colleagues [17], no significant difference between the groups (pancreas/kidney vs kidney only) in the course of retinopathy and visual acuity was reported at least with a mean follow-up period of 24 months. D espite physiological control of blood glucose over a minimum of 12 months, progression of retinopathy and deterioration of visual acuity could be observed. No marked difference in the rate of progression was found between the study and the control group (kidney only group) whether retinopathy was mild or advanced. The results suggested however that pancreatic grafting has late beneficial effects which became obvious after 36 months post-transplant [17].

In a recent long-term study with a mean observation time of 40 months, retinopathy regressed in $9 \%$ (4 out of 45 eyes), stabilized in $73 \%$ and progressed in $18 \%$ of pancreas recipients while in the control group $34 \%$ ( 14 out of 26 eyes) stabilized and $46 \%$ deteriorated $(p<0.03)$ [18]. In the two patients of the study group showing a clear improvement, the grade of retinopathy was mild indicating that amelioration can only be expected at early stages of retinopathy.

In other studies with shorter observation times and smaller numbers of patients, pancreatic transplantation led to a stabilization $[19,20]$ or a progression of diabetic retinopathy [21]. The influence of combined kidney/pancreas grafting on the progression of diabetic retinopathy has been thoroughly studied in a large series of patients ( $n=51$ pancreas/kidney and $\mathrm{n}=21$ kidney only recipients). U nfortunately, data were analysed only after a 1-year follow-up period [22], which is certainly too short to see an amelioration. The authors found no evidence that normalization of glucose metabolism had any influence on the progression or regression of advanced retinopathy: changes in combined transplanted vs kidney transplanted patients when considering the overall retinopathy score were: 34 vs $25 \%$ regression, 44 vs $45 \%$ no change, 22 vs $30 \%$ progression ( $p=0.7$ ).

The most extensive prospective study on retinopathy after pancreatic transplantation was performed in 30 pancreas/kidney recipients with 15 kidney recipients as control subjects [23]. In 27 of the study group and 13 of the control group the follow-up period was longer than 30 months (mean 52 months). In both groups retinopathy remained stable; a closer look at the few patients who did not receive laser treatment prior to transplantation ( 14 study and 6 control eyes) revealed that 4 control eyes significantly deteriorated with a retinopathy score of 2.8 points while the mean retinopathy score remained stable in the pancreas transplant recipients despite the fact that glycosylated haemoglobin was clearly below $10 \%$ in the control group (mean $\mathrm{HbA}_{1} 8.4 \%$, normal $<8 \%$ ), which seems to be of great importance for the development and progression of retinopathy [24-26].

In conclusion, while chronic hyperglycaemia is the most important risk factor for the development and progression of retinopathy [2], these data suggest that advanced diabetic retinopathy might not benefit from pancreatic grafting. H owever, one has to keep in mind that almost all studies except one had a short observation time and that at least $80 \%$ of the patients [23] had received panretinal laser coagulation prior to transplantation, which has been amply demonstrated to lead to a low but stable function of the retina and make interpretation of any therapeutic intervention very difficult.

\section{Nephropathy}

D iabetic nephropathy is one of the most severe lifethreatening complications in IDDM patients. Good metabolic control can prevent or reverse diabetic renal lesions in animals [27-31] and in humans [2, 32, 
Table 1. M orphometric analysis of renal biopsies in pancreas plus kidney vs kidney recipients [42]

\begin{tabular}{|c|c|c|c|c|}
\hline Patients & $\begin{array}{l}\text { M ean glomerular volume } \\
\left(\times 10^{6} \mu \mathrm{m}^{3}\right)\end{array}$ & $\begin{array}{l}\text { M esangial volume fraction } \\
\left(\mu \mathrm{m}^{3} / \mu \mathrm{m}^{3}\right)\end{array}$ & $\begin{array}{l}\text { M esangial vol./glomerulus } \\
\left(\times 10^{6} \mu \mathrm{m}^{3}\right)\end{array}$ & $\begin{array}{l}\text { BMT thickness } \\
(\mathrm{nm})\end{array}$ \\
\hline \multicolumn{5}{|c|}{ Pancreas plus kidney recipients } \\
\hline & $\begin{array}{l}1.80 \pm 0.55 \\
(1.06-3.02)\end{array}$ & $\begin{array}{l}0.19 \pm 0.07 \\
(0.09-0.31)\end{array}$ & $\begin{array}{l}0.34 \pm 0.14 \\
(0.13-0.54)\end{array}$ & $\begin{array}{l}499 \pm 124 \\
(310-790)\end{array}$ \\
\hline \multicolumn{5}{|c|}{ Kidney only recipients } \\
\hline & $\begin{array}{l}2.47 \pm 0.73 \\
(1.63-4.44)\end{array}$ & $\begin{array}{l}0.31 \pm 0.10 \\
(0.15-0.46)\end{array}$ & $\begin{array}{l}0.80 \pm 0.33 \\
(0.36-1.55)\end{array}$ & $\begin{array}{l}545 \pm 116 \\
(359-800)\end{array}$ \\
\hline$p$ value & 0.02 & 0.004 & 0.001 & 0.17 \\
\hline
\end{tabular}

$\mathrm{D}$ ata are mean $\pm \mathrm{SD}$ (and range)

33] and the impact of improved diabetes care has led to a marked reduction in the incidence of diabetic nephropathy in young IDDM patients [34]. Normal kidneys transplanted into diabetic individuals can develop structural abnormalities such as mesangial enlargement and basement membrane thickening 2 to 4 years post-transplant [35-38]. A Ithough the degree of light microscopical changes correlated with the serum creatinine of the patients, it is likely that recurrent nephropathy will be of major clinical significance only in those patients who will have a very long renal graft survival. The effects of pancreatic grafting on prevention or reversal of diabetic nephropathy have been evaluated in two centres. The Stockholm G roup first presented preliminary evidence that basement membrane thickness (B M T) in biopsies from diabetic recipients of combined kidney and pancreas transplants was within the normal range ( 291 to $434 \mathrm{~nm}$ 12 to 48 months post-transplant) while it was significantly increased in diabetic recipients of kidney transplants ranging from 309 to $1017 \mathrm{~nm} 13$ to 105 months after transplantation [36, 39, 40]. R ecently these results were confirmed in a larger series of patients (number of patients/biopsies: 20/36 pancreas and kidney recipients, 30/36 kidney only recipients). When biopsies were taken one to 6,8 years after transplantation there was a significant difference in B M T [41]. In the pancreas/kidney group $91.7 \%$ had $B M T$ values within 2 SD of normal while in the kidney only group $35.3 \%$ had a normal B M T. In a semiquantitative score from 0 to 9 including light microscopical parameters $6.7 \%$ in the combined group but $45.8 \%$ in the kidney group had a score of greater than 3. The relative mesangial volume was normal in $75 \%$ ( $<2.5$ years post-transplant) and $82 \%$ ( $>2.5$ years post-transplant) in patients after simultaneous pancreas/kidney transplantation. In contrast to diabetic kidney recipients the relative volume of the mesangium was normal only in $11 \%$ and $12 \%$ of biopsies ( $<2.5$ and $>2.5$ years after transplantation respectively). From these data it was concluded that pancreatic grafting with subsequent long-term normalization of blood glucose can prevent or reduce typical signs of diabetic nephropathy in kidney allografts.
The M inneapolis group performed a kidney biopsy study in 12 IDDM patients 1 to 7 years after renal transplantation and repeated the biopsies 23 months to 10 years after pancreas transplantation. The data were compared with specimens of renal biopsies in 13 kidney recipients under conventional insulin therapy [42]. In Table 1 the main morphological findings of this study are summarized. A fter pancreas grafting no progression was detected in any structural measure of the glomerulus. In addition, glomerulopathy was significantly less in kidneys after pancreas transplantation supporting the notion that normoglycaemia can prevent the progression of diabetic nephropathy. In contrast to Wilczek et al. [41], however, there was no significant difference in the BMT between both groups of patients suggesting different pathogenetic mechanisms in the two types of glomerular lesions.

In a second study renal biopsies were taken before and 5 years after successful pancreas transplantation from 13 non-uraemic IDDM patients with microand macroalbuminuria and compared with baseline and 5-year-biopsy specimens from 10 ID D M patients without transplantation [43]. BMT did not significantly change in the groups ( $603 \pm 139$ vs $565 \pm 111$ $\mathrm{nm}$ in the transplant group and $594 \pm 151$ vs $609 \pm$ $160 \mathrm{~nm}$ in the control group) nor was there a difference between the groups. M esangial fractional volume increased significantly in both groups and there was no difference between pancreas transplant recipients and the diabetic patients. M ean glomerular volume was smaller after transplantation and the total volume of mesangium per glomerulus did not change in the pancreas recipients while it increased in the control patients. Creatinine clearance fell in the transplant recipients ( $102 \pm 21$ to $68 \pm 24 \mathrm{ml} / \mathrm{min}$ per $1.73 \mathrm{~m}^{2}$ ) while it remained unchanged in the control group ( $79.6 \pm 8.8$ vs $79.6 \pm 17.7 \mathrm{ml} / \mathrm{min}$ per $1.73 \mathrm{~m}^{2}$ ). The fall in glomerular filtration rate occurred in the first year post-transplant and remained unchanged thereafter. Since function and morphology of native or transplanted kidneys can be severely changed by cyclosporin which exerts specific nephrotoxicity [44] and by acute and chronic allograft rejection, the results of these studies have to be interpreted with 
caution and have to be confirmed by a greater number of kidney biopsies and by renal function studies.

\section{Peripheral microcirculation}

Peripheral microcirculatory disturbances are important causes of nutritional and infectious complications, especially in the lower extremities of diabetic patients [45]. N on-invasive methods measuring nutritional and total skin blood flow have been used in pancreas recipients [46-49].

Transcutaneous oxygen tension $\left(\operatorname{tcpO}_{2}\right)$ on the foot increased significantly from $46 \pm 2$ to $63 \pm 3 \mathrm{mmHg}$ (normal values: $67 \pm 7 \mathrm{mmH} \mathrm{g}$ ) 3 years after pancreas and kidney transplantation [47]. In contrast, in kidney only recipients there was no significant amelioration of $\mathrm{tcpO}_{2}$ ( $44 \pm 0.3$ to $\left.41 \pm 2 \mathrm{mmH} \mathrm{g}\right)$.

Vascular reactivity also increased markedly. When $\operatorname{tcpO}_{2}$ was monitored prior to, during and after $3 \mathrm{~min}$ suprasystolic occlusion, reoxygenation time of the foot decreased from $224 \pm 12$ to $114 \pm 6$ s (normal value: $79 \pm 2 \mathrm{~s}$ ) in pancreas/kidney recipients, while it increased from $219 \pm 7$ to $244 \pm 10$ s in kidney only recipients [47].

U sing laser Doppler fluxmetry to evaluate total skin microcirculation, the resting flow increased from $33 \pm 12$ to $67 \pm 11 \mathrm{~mm}$ (normal $66 \pm 11 \mathrm{~min}$ ) 38 months after combined kidney/pancreas transplantation [49]. A Iso peak flow measurements after 1 min of arterial occlusion ( $=200 \mathrm{mmH} \mathrm{g}$ ) were higher post-transplant.

Videophotometric capillaroscopy of the nailfold capillaries of the fingers measuring nutritional skin microcirculation also revealed an increase both during rest and reactive hyperaemia post-transplant [49]. However, a delayed time to peak hyperaemia was found at baseline ( 2 months post-transplant) and was even more impaired 38 months after pancreatic grafting which is in contrast to the findings of $A$ bendroth et al. [47] measuring vascular reactivity with $\mathrm{tcpO}_{2}$. When morphometric analyses of nailfold capillaries were performed using computer-assisted fluorescence intravital microscopy [50] 1 to 12 months post-transplant the morphometric characteristics such as shape, size, configuration, tortuosity, number and density of distribution were similar and very much comparable to diabetic patients and patients pretransplant. However, 12 to 30 months later the density of distribution of the capillaries had increased although thin-walled capillaries, single-file blood cell movement and capillary tortuosity were still present.

The effects of pancreatic grafting on skin temperature have been measured with an electronic thermistor and with computerized telethermography. While Jörneskog et al. [49] did not see any change, Landgraf et al. [46] found a significant increase of skin temperature in pancreas/kidney recipients
$\left(\Delta 1.92 \pm 0.07^{\circ} \mathrm{C}\right) \quad$ while kidney only recipients showed no significant improvement $(\Delta 0.36 \pm$ $0.02^{\circ} \mathrm{C}$ ) after the observation time of 9 months.

$\mathrm{M}$ icrovascular permeability is increased in IDDM $[51,52]$. U sing sodium fluorescein the flow of the capillaries can be visualized under fluorescence epi-illumination and its leakage into the neighbouring intercapillary space videotaped [50]. While it took $187 \pm$ $42 \mathrm{~s}$ to measure fluorescence leakage from nailfold capillaries in healthy non-diabetic control subjects, the diabetic patients pretransplant leaked at $30 \pm 17 \mathrm{~s}(p<0.001)$. The leakage time post-transplant increased significantly: $0-3$ months: $30 \pm 17 \mathrm{~s}$; 12 months $155 \pm 76 \mathrm{~s} ; 12$ to 30 months: $178 \pm 22 \mathrm{~s}$ ( $\mathrm{p}<$ 0.001 ). Whether cyclosporin adds to the reduction of microvascular permeability cannot be ruled out from this study, since it has been shown that this immunosuppressant is beneficial in nephrotic patients [53].

\section{Neuropathy}

A $n$ intra-individual follow-up as well as the inclusion of kidney graft recipients as control subjects are mandatory in order to answer the crucial question of whether pancreatic transplantation prevents, arrests or reverses neuropathy, or solely elimination of uraemia leads to improvements of neuropathy in diabetic kidney recipients.

\section{Autonomic neuropathy}

There are only a few studies examining autonomic nerve function after transplantation. Symptoms of autonomic dysfunction improved, mainly in pancreas/kidney recipients [54], but the improvements were only marginal within the observation time of 36 months.

The $R-R$ variation of heart rate during deep breathing, mainly a measure of parasympathetic vagal function, is low prior to or immediately after transplantation. There was only a minor improvement of the autonomic index [55] after an observation time of 42 months, when comparing the results with ID D M patients awaiting transplantation or after graft failure. The difference between maximal and minimal heart rates during deep breathing ( 6 times per min) changed from $8.8 \pm 1.6$ to $10.7 \pm 3.0$ (NS) in the pancreas/kidney recipients while in diabetic kidney recipients it decreased from $8.4 \pm 4.2$ to $5.8 \pm 1.6$ (NS). H owever, there was a significant difference between both groups at the end of the study. Solders et al. [56] found an ameliorated $R-R$ variability 4 years after transplantation, but this was true both for kidney/pancreas and renal graft recipients. The other studies [54, 57-59] could not demonstrate any significant change in beat-to-beat variation. 
Small nerve fibre function (sweating and temperature discrimination) did not improve 2 years after pancreas/kidney transplantation [60].

A Ithough there was no marked change in cardiovascular reflexes, delayed gastric liquid emptying [61] and overall gastric emptying as well as electrogastrographic recording of gastric rhythm $[62,63] \mathrm{im}$ proved more in patients after pancreas-kidney when compared with kidney-alone transplantation.

D espite small or no changes in autonomic nerve function, indicating that thin myelinated and unmyelinated nerve fibres recover less or at a slower rate than thick myelinated fibres after pancreatic grafting, patients with a functioning pancreas transplant had much better survival rates than patients with a failed graft and also better than IDDM patients with autonomic neuropathy but without pancreas transplantation [64].

Peripheral sensory-motor polyneuropathy

In contrast to autonomic dysfunction, peripheral sensory-motor polyneuropathy improved in most studies considering group comparisons as well as intraindividual longitudinal data.

The symptom score improved in both pancreaskidney and in the kidney alone transplanted patients after a 2-year follow-up, but deteriorated thereafter in the diabetic kidney recipients while in the pancreas/kidney grafted patients the symptoms improved further [65]. The neurological disability score including muscle power, sensation and tendon reflexes, however, showed no significant improvements in both groups $[55,56,65,66]$.

The neurophysiological measurements demonstrated that motor and sensory nerve conduction velocities increased much more in pancreas/kidney graft recipients than in kidney transplanted diabetic patients [46, 55-57, 59, 64-67]. E arly improvements of nerve conduction by elimination of uraemia in the first 2 years post-transplant $[55,56,65]$ is abolished by progression of diabetic neuropathy in kidney recipients. O nly the successfully pancreas grafted patients showed a significant and lasting amelioration of polyneuropathy when the observation time was extended to 3 years and more. It is therefore suggested that nerve regeneration [68] and repair after normalization of glucose metabolism seem to be much slower than the amelioration of nerve dysfunction seen after elimination of uraemia by kidney transplantation. In fact, long-term euglycaemia leads to structural improvements of the nerves as reported in a preliminary investigation [69].

Very recently $M$ üller-Felber et al. (unpublished data) accumulated data for both pancreas/kidney and kidney only recipients over an observation time of 6 years. There was a steady increase of nerve conduction velocity in the pancreas grafted patients, while in the kidney transplanted patients nerve conduction velocity decreased although these patients had a perfect long-term metabolic control with a mean glycated haemoglobin of $6.8 \%$ (normal $<6.0 \%)$. Similar results have been published from the Stockholm group [70].

In two studies [55, 65] amplitudes of nerve action potentials, which correlate with the number of axons, did not increase after an observation period between 3 to 4 years. This indicates that improvement of myelin function can occur but that the axonal loss remains unchanged.

I ncreased nerve conduction velocities are different depending on the nerves studied. For example, median and sural sensory NCV s were insignificant [65] or less improved [55] post-transplant when compared to the corresponding motor NCVs, indicating that sensory fibres respond less to improved diabetic metabolism. This is in agreement with an earlier study, which demonstrated that intensified insulin treatment did not result in an improvement of sural NCV [71]. This is however in contrast to the data of the O slo study [72].

Sensory median nerve conduction can be significantly influenced by a high rate of carpal tunnel syndrome pre- and especially post-transplant [73]. This might lead not only to retrograde changes of the nerve fibres in the forearm [74] but is probably also the cause of the smaller increase of median NCV compared with peroneal NCV [65]. Therefore, studies on the median nerve should not be taken as representative of diabetic polyneuropathy.

\section{Macroangiopathy}

A Ithough cardiovascular complications are the main cause of the excess mortality in diabetic patients, the influence of pancreas transplantation on the fate of macrovascular lesions has not been investigated in detail. It is well known that there is an elevated incidence of cerebrovascular events and myocardial infarctions [75-77] as well as of thromboembolic complications [78] after kidney transplantation, and immunosuppressive therapy has been reported to increase the vascular risk profile after cardiac or renal grafting [79-84].

R ecent studies however could demonstrate a favourable effect of pancreas and kidney transplantation on serum lipids [85-89]. While lipid status of subjects with IDDM and renal failure was abnormal before pancreas-kidney transplantation, cholesterol fell sharply during the immediate postoperative period ( $<2$ months), but increased afterward. H D L-cholesterol rose significantly in the same time frame from $1.07 \pm 0.09$ to $1.31 \pm 0.08 \mathrm{mmol} / \mathrm{l}$ and triglycerides decreased from $5.85 \pm 0.56$ to $4.54 \pm 0.48 \mathrm{mmol} / /$ [88]. 
There was also a remarkably normal postprandial triglyceride clearance in pancreas recipients after an oral fat tolerance test due to a high post-heparin lipoprotein lipase activity [86]. A decrease of triglycerides and total cholesterol was also noted in another study [87], however, these lipid changes were seen both in kidney only and kidney/pancreas recipients. Similar data were found by us [90] in which the levels of triglycerides, total as well as LDL - and HDL-cholesterol, were very similar in pancreas/kidney $(n=26)$ and kidney only $(n=23)$ recipients. These data have been confirmed by a recently published extensive study showing total cholesterol and HDL and LD L -cholesterol very comparable in diabetic patients with end-stage renal disease and in pancreas/ kidney and kidney only recipients [89]. But triglycerides were significantly lower in pancreas/kidney recipients when compared to diabetic patients prior to and after kidney grafting. The same result was obtained with VLDL-cholesterol and VLDL-triglycerides as well as LD L - and H D L -triglycerides. A poprotein $B$ was lower and A po A 1 higher in the pancreas recipients. However, compared with a non-diabetic control population there was not a complete normalization of the lipoprotein profile, since V LD L particles and the triglyceride content of LDL - and HDL persisted after pancreas transplantation. It is suggested that insulin resistance with a higher ratio of peripheral to hepatic insulin levels is probably the cause of these lipoprotein abnormalities [89]. HD L cholesterol was remarkably high after transplantation [91]. Elevated HDL-cholesterol levels have been reported after transplantation $[79,91]$ and after intensified insulin therapy [92]. The latter is probably related to higher peripheral insulin levels as in pancreas grafting leading to activation of tissue lipoprotein lipase with subsequent enhanced formation of HDL cholesterol from V LDL particles [93].

$\mathrm{H}$ ypertension is more prevalent in renal transplant recipients than in healthy control subjects [94] with a persistent risk of cardiovascular mortality in these patients [95], however with a marked reduction of excess mortality in kidney recipients when compared to dialysis patients. Simultaneous pancreas/kidney transplantation was associated with an improvement of arterial hypertension $[90,96]$, but there is still a marked elevation of blood pressure in successfully grafted patients with antihypertensive therapy necessary in $65 \%$ of them. B esides persisting hypertension in endstage renal disease after successful pancreas and/or renal transplantation, blood pressure elevation is almost certainly partially related to cyclosporin therapy.

Fibrinogen is a potent predictor of cardiovascular events [97]. A fter pancreas transplantation there was a significant elevation of fibrinogen concentration (4.16 $\pm 0.75 \mathrm{~g} / \mathrm{l}$ [94]) and also of alpha - -macroglobulin another acute-phase protein. B oth are main determinants of plasma viscosity. Indeed plasma viscosity was markedly increased in this group of patients [90].

Despite significant improvements in glucose and lipid metabolism there remains an elevated risk for cardiovascular events in patients after pancreas/kidney transplantation which might be attributable to hypertension, hyperfibrinogenaemia and impaired haemorheology although clear-cut clinical endpoints of cardiovascular complications like stroke, myocardial infarction and amputation have not been studied.

\section{Quality of life}

There is increasing recognition that expensive and incisive therapeutic regimens which aim to prolong or ameliorate life in chronic illnesses must be assessed in terms of their impact on quality of life (QOL) in addition to more traditional measures such as morbidity and mortality. This is especially true for medical interventions such as organ transplantation which carry a considerable risk and involve many socio-economic aspects. In recent years it has become possible to measure in detail Q O L although there is some disagreement about the most suitable approach. Some workers prefer structured inpatient interviews, some an evaluation by the physician and others use self-administered questionnaires. It is important to stress that all instruments used should be disease- and treatment-specific.

There are a number of cross-sectional studies on QOL in pancreas transplant recipients. Nakache et al. [98] were the first to use the QOL index of Spitzer. They reported on the benefit of combined pancreas-kidney transplantation (group 1) in comparison to diabetic kidney only recipients (group 2). In group $190 \%$ but in group 2 only $50 \%$ had full-time occupations, the amount of lost work days decreased by $44 \%$ in group 1 but was unchanged in group 2, also hospitalization was significantly less in group 1 than in group 2 ( 12 vs 25 days). In addition, pancreas-kidney recipients achieved a better $\mathrm{QOL}$ in the three health concepts physical well-being, sole functioning and perception of self. In an extensive analysis 131 pancreas transplant recipients who were 1 to 11 years post-transplant were studied [99]. Patients with functioning pancreas grafts $(n=65)$ expressed in comparison with non-functioning pancreas graft recipients but good kidney function $(n=66)$ more overall satisfaction with their life ( 68 vs $48 \%$ ), felt healthier post-transplant ( 89 vs $25 \%$ ) and reported that they were able to care for themselves and their daily activities ( 78 vs $56 \%$ ). Similar results although less convincing had been published previously $[100,101]$. The most detailed study of the different aspects of QOL was performed applying a disease-specific self-administered questionnaire (217 questions and various subscales) [102]. The group of 
157 patients was categorized into 6 subgroups: patients pretransplant without dialysis $(n=29$; $A$ ), pretransplant under dialysis ( $n=44 ; B$ ), post-transplant with functioning kidney and pancreas $(n=31 ; C)$, post-transplant with funtioning kidney only $(n=29$; D), post-transplant after rejection of both organs $(n=15 ; E)$ and post-transplant after unsuccessful single pancreas grafting and good renal function $(n=9$; $F$ ). The results indicated a much better quality of life in $C+D$ as compared to the other groups, especially for their satisfaction with physical capacity, leisuretime activities and overall QOL. There was no marked improvement in the vocational situation after successful grafting indicating a highly attractive social network with little force of restarting professional life after successful transplantation in the country of origin of this study (Germany). It was also interesting to note that in general all scores were highest in patients with functioning pancreas-kidney grafts but without significant differences to the patients with functioning kidney only, suggesting that elimination of uraemia with the necessity of dialysis treatment has the greatest impact on the amelioration of $\mathrm{QOL}$, although the small sample size may account for the lack of significance that occurred with the various measures. Comparable conclusions have been drawn by $\mathrm{M}$ ilde et al. [103] using a similar number of patients.

Since these promising results have been obtained by cross-sectional studies which may be influenced by sample and selection biases or time effects, prospective studies have been initiated. In a preliminary 1-year follow-up study using the Medical Outcome Study H ealth Survey 36-Item Short Form (SF-36) [104] and comparing pancreas-kidney, kidney only and IDDM control subjects improvement of general health perception, social function, vitality and pain was seen in both transplanted groups, but physical limitations improved only in pancreas-kidney recipients [105]. The total SF-36 score was significantly higher in the pancreas/kidney recipients when compared to the kidney only group. U sing the same instrument for the measurement of $Q O L$ as for the cross-sectional analysis [102] overall Q O L, financial situation, physical capacity, job situation, sexual and leisure time activities increased from pretransplant to $22 \pm 4$ months after pancreas/kidney transplantation. D ue to the low number of patients, however, no statistical significance was observed [106]. D uring an observation of 6 months post-transplant using a twogroup (kidney alone and kidney/pancreas) pre/posttransplant design and the Sickness I mpact Profile as the instrument with 12 behavioural dimensions $\mathrm{H}$ athaway et al. [107] found a higher degree of improvement in the pancreas/kidney group ( $80 \%$ of the scales improved), while only $40 \%$ were better for the kidney alone group. In the most recent study [108] life and health qualities increased significantly in both pancreas/kidney and kidney alone transplant recipients during an observation time of 6 or more months post-transplant, but there were no significant group differences suggesting that achieving one's transplantation goal, functioning organ(s), has a major impact on QOL. In a long-term study (7 years post-transplant) although with a rather low number of patients in each group (kidney/pancreas group $1 \mathrm{n}=8$; kidney alone group $2 \mathrm{n}=10$ ) physical well-being (86 vs $30 \%$ ), perception of health (71 vs $20 \%$ ), physical abilities ( 86 vs $10 \%$ ) and the re-integration-to-normal-living index ( 86 vs $40 \%$ ) were significantly higher in group 1 [109].

\section{Conclusion}

Pancreatic transplantation has improved considerably in recent years for patient and graft survival (80-90\% 1-year graft survival in the experienced centres). In contrast to the single centre retrospective analysis of mortality which showed a marked reduction in 3-year patient survival in pancreas/kidney recipients vs diabetic kidney recipients (68 vs $90 \%$ [110]) the International Pancreas Transplant R egistry clearly finds that pancreas transplantation is now a safe procedure and patient survival is between 90 and $100 \%$ in centres specialized in the surgical procedure, in preoperative patient selection as well as in peri- and post-operative organ recipient care [4]. Therefore there is no reason not to make uraemic IDD M patients dialysis free and insulin-independent by simultaneous or consecutive kidney-pancreas transplantation. Kidney transplantation recipients are already obliged to undergo immunosuppression and the surgical risk for an additional pancreatic grafting is low. H owever, it is important to mention that early post-transplant morbidity is greater after combined pancreas/kidney grafting when compared to renal transplantation alone [111, 112].

For extremely labile, non-uraemic diabetic individuals with poor quality of life due to hypoglycaemia unawareness or fluctuating hypoglycaemia and ketoacidosis a pancreas transplant alone might be an available option especially when using immunosuppressive drugs such as mycophenolate mofetil and tacrolimus.

Careful analysis of the impact of pancreatic transplantation on secondary complications has demonstrated that even in advanced stages of diabetes, normalization of glucose metabolism has a series of vascular and neurological benefits and significantly improves many aspects of quality of life. Recently it has been argued that pancreas transplantation should be stopped, since islet transplants, transplantation of encapsulated islets (human and pig), closed-loop insulin pump devices and/or gene therapy are around the corner or are already working. We are all enthusiastically waiting for a major breakthrough in this 
field, but what do we do with the increasing numbers of patients who have major diabetes problems today? A fter careful information and clinical investigation they should be offered a pancreas transplant!

A cknowledgements. I am indebted to Prof. W. L and, D r. W.-D IIIner, D r. D. A bendroth from the Transplantation Center M unich and D r. J. N usser, D r. R. Scheuer, D r. W. Piehlmeier, D r. J. M ojto and M S. C. G rünfeldt and M s. A. Frühbeis from the Department of Internal Medicine, U niversity of Munich for their invaluable co-operation during recent years. Without the continuous help from our graft recipients most of the data obtained would not have been possible. Thanks to all of them.

\section{References}

1. World Health O rganization (1985) D iabetes mellitus. R eport of a WHO Study Group. Technical R eport Series 727. WHO Geneva

2. The Diabetes Control and Complications Trial Research Group (1993) The effect of intensive treatment of diabetes on the development and progression of long term complications in insulin-dependent diabetes mellitus. N Engl J M ed 329: $977-986$

3. Nathan D M (1993) L ong-term complications of diabetes mellitus. N Engl J M ed 328: 1676-1685

4. Sutherland DER, G rüssner A (1995) Long-term function ( $>5$ years) of pancreas grafts from the International Pancreas Transplant R egistry database. Transplant Proc 26: 407411

5. Hering BJ, Schultz A O, Geier C, Bretzel RG, Federlin K (1995) I nternational I slet Transplant R egistry. Fresenius, G ermany G iessen 5: 2-28

6. Landgraf R (1991) Fetal islet cell transplantation: state of the art. In: L and W, D ossetor J B (eds) O rgan replacement therapy: ethics, justice and commerce. Springer, $\mathrm{H}$ eidelberg, $\mathrm{pp}$ 484- 490

7. R each $G$ (1989) A rtificial or bioartificial systems for the totally automatic treatment of diabetes mellitus: the gap between the dream and the reality. D iab N utr M etab 2: 165-170

8. Williams W (1894) N otes on diabetes treated with extract and by grafts of sheep's pancreas. Br M ed J 2: 83

9. Landgraf R, A bendroth D, L and W, Bolinder J (eds) (1991) Secondary complications and quality of life after successful pancreatic transplantation in type 1 (insulin-dependent) diabetes mellitus. Diabetologia 34 [Suppl 1]: 1-195

10. Sutherland DER, G rüssner A, M oudry-M unns K (1994) International Pancreas Transplant R egistry R eport. Transplant Proc 26: 407-411

11. Östman J, Bolinder J, G unnarsson R, B rattström C, Tyden G, Wahren J, G roth C (1989) E ffects of pancreas transplantation on the metabolic and hormonal profiles in IDDM patients. Diabetes 38 [Suppl 1]: 88-93

12. L andgraf $R, N$ usser J, R iepl R L et al. (1991) M etabolic and hormonal studies of type 1 (insulin-dependent) diabetic patients after successful pancreas and kidney transplantation. Diabetologia 34 [Suppl 1]: S61-S67

13. Pfeffer F, Nauck M A, Benz S, et al (1996) D eterminants of a normal (versus impaired) oral glucose tolerance after combined pancreas-kidney transplantation in IDDM patients. Diabetologia 39: 462-468

14. Feldt-R asmussen $B, M$ athiesen $E R$, J ensen $T$, $L$ auritzen $T$, Deckert T (1991) E ffect of improved metabolic control on loss of kidney function in type 1 (insulin-dependent) diabetic patients: an update of the Steno studies. Diabetologia 34: 164- 170

15. Dahl-J ørgensen $\mathrm{K}$, B rinchmann- $\mathrm{H}$ ansen $\mathrm{O}$, Bangstad $\mathrm{H}-\mathrm{J}$, $\mathrm{H}$ anssen KF (1994) Blood glucose control and microvascular complications - what do we now ? Diabetologia 37: 11711177

16. Ulbig M, Kampik A, Landgraf R, Land W (1987) The influence of combined pancreatic and renal transplantation on advanced retinopathy. Transplant Proc 19: 3554-3556

17. Ramsay RC, G oetz FC, Sutherland DER et al. (1988) Progression of diabetic retinopathy after pancreas transplantation for insulin-dependent diabetes mellitus. N Engl J Med 318: 208-214

18. Königsrainer A, M iller K, Steurer W et al. (1991) Does pancreas transplantation influence the course of diabetic retinopathy. D iabetologia 34 [Suppl 1]: 86-88

19. Bandello F, Vigano C, Secchi A et al. (1991) E ffect of pancreas transplantation on diabetic retinopathy. A 20 case report. Diabetologia 34 [Suppl 1]: 92-94

20. Zech J C, Trepsat D, Cain-G ueugnon M , L efrançois N, M artin X, D ubernard M (1991) O phthalmological follow-up of type 1 (insulin-dependent) diabetic patients after kidney and pancreas transplantation. D iabetologia 34 [Suppl 1]: 89-91

21. Petersen M R, Vine A K (1990) Progression of diabetic retinopathy after pancreas transplantation. Ophthalmology 97: 496-502

22. Wang $Q$, K lein R, M oss SE, K lein BE K, H oyer C, Burke K, Sollinger HW (1994) The influence of combined kindneypancreas transplantation on the progression of diabetic retinopathy. Ophthalmology 101: 1071-1076

23. Scheider A, M eyer-Schwickerath V, Nusser J, L and W, L andgraf R (1991)D iabetic retinopathy and pancreas transplantation: a 3-year follow-up. D iabetologia 34 [Suppl 1]: 95-99

24. K lein $R$, K lein BE, M oss SE, D avis M D, D eM ets D L (1988) G lycosylated hemoglobin predicts the incidence and progression of diabetic retinopathy. JA M A 260: 2864-2871

25. Janka HU, Warram J H, R and L I, K rolewski A S (1989) R isk factors for progression of background retinopathy in longstanding ID D M. D iabetes 38: 460-464

26. Warram J H, M anson J E, K rolewski A S (1995) G lycosylated hemoglobin and the risk of retinopathy in insulin-dependent diabetes mellitus. N E ngl J M ed 332: 1305-1306

27. Steffes M W, B rown D M, B asgen J M, M auer SM (1980) A melioration of mesangial volume and surface al terations following islet transplantation in diabetic rats. D iabetes 29: 509-515

28. O rloff M J, Yamanaka N, G reenleaf GE, H uang Y-T, H uang $D-G$, L eng XS (1986) R eversal of mesangial enlargement in rats with longstanding diabetes by whole pancreas transplantation. D iabetes 35: 347-354

29. O rloff J M, M acedo C, M acedo A, G reenleaf GE (1987) Comparison of whole pancreas and pancreatic islet transplantation in controlling nephropathy and metabolic disorders of diabetes. A nn Surg 206: 324-334

30. Petersen J, R oss J, R abkin R (1988) E ffect of insulin therapy on established diabetic nephropathy in rats. Diabetes 37 : $1346-1350$

31. Kern TS, Engermann R L (1990) A rrest of glomerulopathy in diabetic dogs by improved glycemic control. D iabetologia 33: 522-525

32. K rolewski A S, Laffel L M B, K rolewski M, Q uinn M, Warram $\mathrm{H}$ (1995) G lycosylated hemoglobin and the risk of microalbuminuria in patients with insulin-dependent diabetes mellitus. N Engl J Med 332: 1251-1255

33. R eichard P, Nilsson B-Y, R osenquist U (1993) The effect of long-term intensified insulin treatment on the development of microvascular complications of diabetes mellitus. N E ngl J M ed 329: 304-309

34. Bojestig M , A rmquist HJ, H ermansson G, K arlberg BE , L udvigsson J (1994) D eclining incidence of nephropathy in insulin-dependent diabetes mellitus. N E ngl J M ed 330: 15-18

35. M auer SM, Steffes M W, Connett J, Najarian J S, Sutherland DER, Barbosa J (1983) The development of lesions in the glomerular basement membrane and mesangium after transplantation of normal kidneys to diabetic patients. Diabetes 32: 948-952 
36. B ohmann SO, Wilczek H, Jaremko G, L undgren G (1984) R ecurrence of diabetic nephropathy in human renal allografts: preliminary report of a biopsy study.Transplant Proc 16: 649653

37. M auer SM, Goetz FC, M cH ugh LE et al. (1989) L ong-term study of normal kidneys transplanted into patients with type 1 diabetes. Diabetes 38: 516-523

38. Ø sterby R, N yberg G, H edman L, K arlberg I , Persson H, Svalander C (1991) K idney transplantation in type I (insulin-dependent) diabetic patients. Early glomerulopathy. Diabetologia 34: 668-674

39. B ohman SO, Tydén G, Wilczek $H$ et al. (1985) Prevention of kidney graft diabetic nephropathy by pancreas transplantation in man. D iabetes 34: 306-308

40. B ohman SO, Wilczek H, Tydén G, Jaremko G, L undgren G, G roth CG (1987) R ecurrent diabetic nephropathy in renal allografts placed in diabetic patients and protective effect of simultaneous pancreatic transplantation. Transplant Proc 19: 2290-2293

41. Wilczek HE, Jaremko G, Tydén G, G roth CG (1995) E volution of diabetic nephropathy in kidney grafts. Transplantation 59: $51-57$

42. Bilous RW, M auer SM, Sutherland DE R, Najarian IS, G oetz FC, Steffes M W (1989) The effects of pancreas transplantation on the glomerular structure of renal allografts in patients with insulin-dependent diabetes. N Engl J M ed 321: 80-85

43. Fioretto $P$, M auer SM, Bilous RW, G oetz FC, Sutherland DER, Steffes M W (1993) E ffects of pancreas transplantation on glomerular structure in insulin-dependent diabetic patients with their own kidneys. L ancet 342: 1193-1196

44. Fuetren G, M ihatsch J (1992) R isk factors for cyclosporine induced nephropathy in patients with autoimmune diseases. $\mathrm{N}$ Engl J M ed 326: 1654-1660

45. Tooke JE (1995) M icrovascular function in human diabetes. A physiological perspective. Diabetes $44: 721-726$

46. Landgraf R, N usser J, M üller W, et al (1989) Fate of late complications in type 1 diabetic patients after successful pancreaskidney transplantation. D iabetes 38 [Suppl 1]: 33-37

47. A bendroth D, Schmand J, L andgraf R, IIIner WD, L and W (1991) Diabetic microangiopathy in type 1 (insulin-dependent) diabetic patients after successful pancreatic and kidney or solitary kidney transplantation. D iabetologia 34 [Suppl 1]: 131-134

48. Jörneskog G , Tydén G , B olinder J, Fagrell B (1990) D oes combined kidney and pancreas transplantation reverse functional diabetic microangiopathy? Transplant I nt 3: 167-170

49. Jörneskog G, Tydén G, Bolinder J, Fagrell B (1991) Skin microvascular reactivity in fingers of diabetic patients after combined kidney and pancreas transplantation. D iabetologia 34 [Suppl 1]: 135-137

50. Cheung A TW, Cox KL, A hlfors CE, Bry WI (1993) R eversal of microangiopathy in long-term diabetic patients after successful simultaneous pancreas-kidney transplants. Transplant Proc 25: 1310-1313

51. Deckert $T$, Feldt-R asmussen $B$, B orch-Johnsen $K$, J ensen $T$, Kofoed-E nevoldsen A (1989) A lbuminuria reflects widespread vascular damage: the Steno hypothesis. D iabetologia 32: $219-226$

52. Jaap A J, Shore A C, G artside IB , G amble J, Tooke JE (1993) Increased microvascular fluid permeability in young type 1 (insulin-dependent) diabetic patients. D iabetologia 36: 648-652

53. M eyrier A (1994) Treatment of nephrotic syndrome with cyclosporin A .W hat remains in 1994? Nephrol D ial Transplant 9: 596-598

54. N usser J, Scheuer R, A bendroth D, IIIner WD, L and W, L andgraf R (1991) Effect of pancreatic and/or renal transplantation on diabetic autonomic neuropathy. D iabetologia 34 [Suppl 1]: 118-120

55. Kennedy WR, Navarro X, Goetz FC, Sutherland DER, $N$ ajarian J S (1990) E ffects of pancreatic transplantation on diabetic neuropathy. N E ngl J M ed 322: 1031-1037
56. Solders G, Tydén G, Persson A, G roth CG (1992) Improvement of nerve conduction in diabetic neuropathy. A followup study after combined pancreatic and renal transplantation. D iabetes 41: 946-951

57. Comi G, Galardi G, A madio S et al. (1991) Neurophysiological study of the effect of combined kidney and pancreas transplantation on neuropathy. A two year follow-up evaluation. D iabetologia 34 [Suppl 1]: 103-107

58. B oucek P, Bartos V, Vanek I, H yzâ Z, Skibová J (1991) Diabetic autonomic neuropathy after pancreas and kidney transplantation. D iabetologia 34 [Suppl 1]: 121-124

59. Vial C, M artin X, Lefrançois N, D ubernard J M, Chauvin F, Bady B (1991) Sequential electrodiagnostic evaluation of diabetic neuropathy after combined pancreatic and renal transplantation. D iabetologia 34 [Suppl 1]: 100-102

60. Kennedy WR, Navarro X, Sutherland DER (1989) Small nerve fiber neuropathy in diabetes mellitus after pancreas transplantation. M uscle N erve 9: 767-768

61. M urat A, Pouliquen B, Cantarovich D et al. (1992) Gastric emptying improvement after simultaneous pancreas and kidney transplantation. Transplant Proc 24: 855

62. G aber A O, H athaway D K, A bell T, Cardoso S, Hartwig M S, E L G ebely S (1994) I mproved autonomic and gastric function in pancreas-kidney vs kidney-alone transplantation contributes to quality of life. Transplant Proc 26: 515-516

63. G aber A O, Cardoso S, Pearson S et al. (1991) Improvement in autonomic function following combined pancreas-kidney transplantation.Transplant Proc 23: 1660-1662

64. N avarro X, K ennedy W R, L oewenson R B, Sutherland D E R (1990) Influence of pancreas transplantation on cardio-respiratory reflexes, nerve conduction, and mortality in diabetes mellitus. D iabetes 39: 802-806

65. M üller-Felber W, Landgraf R, Scheuer R et al. (1993) Diabetic neuropathy 3 years after successful pancreas and kidney transplantation. D iabetes 42: 1482-1486

66. M üller-Fel ber W, L andgraf R, Wagner ST et al. (1991) Followup study of sensory-motor polyneuropathy in type 1 (insulindependent) diabetic subjects after simultaneous pancreas and kidney transplantation and after graft rejection. Diabetologia 34 [Suppl 1]: 113-117

67. Van der V liet JA, N avarro X, K ennedy W R, G oetz FC, N ajarian J S, Sutherland DE R (1988) The effect of pancreas transplantation on diabetic polyneuropathy. Transplantation 45: 368-370

68. Vinik A I, N ewlon PG, L auterio TJ et al. (1995) N erve survival and regeneration in diabetes. $D$ iabetes R eviews 3: 139-157

69. B eggs J L, Johnson PC, O lafsen A G, Cleary CP, Watkins CJ, Targovnik JH (1990) Signs of nerve regeneration and repair following pancreas transplantation in an insulin-dependent diabetic with neuropathy. Clin Transplant 4: 133-141

70. Solders G, Tyden G, Tibell A, Persson A, G roth CG (1995) Improvement in nerve conduction 8 years after combined pancreatic and renal transplantation. Transplant Proc 27: 3091

71. Ziegler D, D annehl K, W iefels K, G ries FA (1992) D ifferential effects of near-normoglycemia for 4 years on somatic nerve dysfunction and heart rate variation in type 1 diabetic patients. D iabet M ed 9: 622-629

72. A mthor K F, D ahl-Jørgensen K, B erg TJ et al. (1994) The effect of 8 years strict glycaemic control on peripheral nerve function in IDDM patients: the O slo Study. D iabetologia 37: 579-584

73. $M$ üller-Felber $W$, L andgraf $R$, R eimers $C D$ et al. (1993) $H$ igh incidence of carpal tunnel syndrome in diabetic patients after combined pancreas and kidney transplantation. A cta Diabetol 30: 17-20

74. Stöhr M, Petruch F, Scheglmann K, Schilling K (1978) R etrograde changes of nerve fibers with the carpal tunnel syndrome. I Neurol 218: 287-293

75. R ao K V, A ndersen R C (1987) The impact of diabetes on vascular complications following cadaver renal transplantation. Transplantation 43: 193-197 
76. Braun WE (1990) L ong-term complications of renal transplantation. K idney Int 37: 1363-1378

77. M ahony JF, Caterson RJ, Pollock CA, Jones $M$, Waugh DA, Sheil A G R (1990) Coronary artery disease is the major late complication of successful cadaveric renal transplantation. Clin Transplant 4: 129-132

78. Vanrenthergem Y, R oels J, Lerut T et al. (1985) Thromboembolic complications and haemostatic changes in cyclosporintreated cadaveric kidney allograft recipients. L ancet i: 9991002

79. Harris K PG, R ussell GI, Parvin SD, Veitch PS, WallsJ (1986) A Iterations in lipid and carbohydrate metabolism attributable to cyclosporin A in renal transplant recipients. B r M ed J 292: 16

80. Isoniemi H, Tikkanen MJ, A honen J, Häyry P (1991) R enal allograft immunosuppression. Comparison of lipid and lipoprotein profiles in blood using double and triple immunosuppressive drug combinations. Transpl Int 4: 130-135

81. Bittar A E , R atcliffe PJ, R ichardson A J, et al. (1990) The prevalence of hyperlipidemia in renal transplant recipients. Transplantation 50: 987-992

82. Barbir M, Banner N, Thompson G R, K hagani A, M itchell A, Yacoub M (1991) R elationship of immunosuppression and serum lipids to the development of coronary arterial disease in the transplanted heart. Int J Cardiol 32: 51-56

83. Stamler JS, Vaughan DE, L oscalzo J (1991) I mmunosuppressive therapy and lipoprotein abnormal ities after cardiac transplantation. A m J Cardiol 68: 389-391

84. K asiske BL (1993) R isk factors for accelerated atherosclerosis in renal transplant recipients. A m J M ed 84: 985-992

85. Bolinder J, Tydén G, Tibell A, G roth CG, Östman J (1991) Long-term metabolic control after pancreas transplantation with enteric exocrine diversion. D iabetologia 34 [Suppl]: 7680

86. Drexel H, Palos G, Königsrainer A et al. (1991) L ong-term follow-up of glycaemic control and parameters of lipid transport after pancreas transplantation. D iabetologia 34 [Suppl 1]: $47-50$

87. Nyberg G, Fager G, M jörnstedt L, O lausson M (1991) M etabolic risk factors for cardiovascular disease in pancreas and kidney transplant recipients. D iabetologia 34 [Suppl 1]: 44-46

88. Larsen J L, Stratta R J, O zaki CF, Taylor RJ, M iller SA, D uckworth WC (1992) Lipid status after pancreas-kidney transplantation. Diabetes Care 15: 35-42

89. La R occa E, Secchi A, Parlavecchia M et al. (1995) Lipoprotein profile after combined kidney-pancreas transplantation in insulin-dependent diabetes mellitus. Transpl Int 8: 190-195

90. M ellinghoff $A C, R$ eininger $A J$, Wurzinger $L J, L$ andgraf $R$ (1994) Cardiovascular risk factors after pancreas- and kidney transplantation. Diabetologia 37 [Suppl 1]: A 37

91. Taylor D O, Thompson JA, H astillo A et al. (1989) Hyperlipidemia after clinical heart transplantation. J H eart Transplant 8: 209-213

92. L opez-V irella M F, Wohltmanns HJ, M ayfield R K, L oadholt CB, Colwell JA (1983) E ffect of metabolic control on lipid, lipoprotein and apolipoprotein levels in 55 insulin-dependent diabetic patients: a longitudinal study. Diabetes 32: 20-25

93. Laakso M, Sarlund $H, E$ hnholm C, Voutilainen $E, A$ ro A, Pyörala K (1987) R elationship between postheparin plasma lipases and high density lipoprotein cholesterol in different types of diabetes. D iabetologia 30: 703-706
94. K asiske BL (1988) Possible causes and consequences of hypertension in stable renal transplant patients. Transplantation 44: 639-643

95. Sánchez J, Pallardó L M, Sánchez P, G arcía J, O rero E, B eneyto J, Cruz J M (1992) R isk factors and prognostic significance of hypertension after renal transplantation. Transplant Proc 24: 2738-2739

96. R aja RW, L evner L, M orris M (1993) Hypertension with combined pancreas-kidney transplants in patients with diabetic nephropathy. Transplant Proc 25: 1190-1191

97. E rnst E, R esch KL (1993) Fibrinogen as a cardiovascular risk factor: a metaanalysis and review of the literature. A nn Int M ed 118: 956-963

98. Nakache R, Tydén G, G roth CG (1989) Q uality of life in diabetic patients after combined pancreas-kidney or kidney transplantation. D iabetes 38: 40-42

99. Zehrer CL, Gross CR (1991) Q uality of life of pancreas transplant recipients. D iabetologia 34 [Suppl 1]: 145-149

100. Voruganti L NP, Sells R A (1989) Quality of life of diabetic patients after combined pancreatic-renal transplantation. Clin Transplantation 3: 78-82

101. Corry R J, Zehr P (1990) Q uality of life in diabetic recipients of kidney transplants is better with the addition of the pancreas.Clin Transplantation 4: 238-241

102. Piehlmeier W, B ullinger M, N usser J, et al. (1991) Q uality of life in type 1 (insulin-dependent) diabetic patients prior to and after pancreas and kidney transplantation in relation to organ function. Diabetologia 34 [Suppl 1]: 150-157

103. M ilde FC, H art L K, Zehr PS (1992) Q uality of life of pancreatic transplant recipients. Diabetes Care 15: 1459-1463

104. Ware J E, Sherboune CD (1992) The M OS 36-item short-form health survey (SF 36): I. Conceptual framework and item selection. Med Care 30: 473-483

105. Zehrer CL, G ross CR (1994) Comparison of quality of life between pancreas/kidney and kidney transplant recipients. 1year follow-up.Transplant Proc 26: 508-509

106. Piehlmeier W, B ullinger M, K irchberger I, et al. (1994) Prospective study of the quality of life in type 1 diabetic patients before and after organ transplantation.Transplant Proc 26: 522-523

107. H athaway DK, H artwig M S, M ilstead J, EImer D, E vans S, G aber A O (1994) Improvement of quality of life reported by diabetic recipients of kidney-only and pancreas-kidney allografts.Transplant Proc 26: 512-514

108. M ilde FK, H art LK, Zehr PS (1995) Pancreatic transplantation. I mpact on the quality of life of diabetic renal transplant recipients. D iabetes Care 18: 93-95

109. Nakache R, Tydén G, G roth CG (1994) L ong-term quality of life in diabetic patients after combined pancreas-kidney transplantation or kidney transplantation. Transplant Proc 26: 510511

110. M anske CL, Wang $Y$, Thomas W (1995) M ortality of cadaveric kidney transplantation versus combined kidney-pancreas transplantation in diabetic patients. L ancet 346: 1658-1662

111. Solinger H W, K nechtle SJ, R eed A, et al. (1991) Experience with 100 consecutive simultaneous kidney-pancreas transplants with bladder drainage. A nn Surg 214: 701-711

112. Rosen CB, Frohnert PP, Velosa JA, Engen DE, Sterioff $S$ (1991) M orbidity of pancreas transplantation during cadaveric renal transplantation. Transplantation 51: 123-127 